\title{
Negative Side Effects Associated with Hearing Aid Use in Adults with Hearing Loss
}

DOI: $10.3766 /$ jaaa. 17118

\author{
Vinaya Manchaiah*†‡§ \\ Harvey Abrams $₫$ \\ Abram Bailey\| \\ Gerhard Andersson\#**
}

\begin{abstract}
Background: The low uptake of hearing aids in the United States has been attributed to a number of reasons, including low perceived hearing disability, limited perceived benefit and cost. Another possible reason may be related to negative side effects associated with hearing aid use.
\end{abstract}

Purpose: The present study was aimed at determining and classifying the negative side effects associated with hearing aid use in adults with hearing loss.

Research Design: The study used a cross-sectional survey design.

Study Sample: Five hundred and twelve participants completed an electronic survey.

Data Collection and Analysis: The data was collected using the negative side effects of hearing aids (NSE-HAs) questionnaire. Data were analyzed using Chi square analysis, principal components analysis, and calculation of Cronbach's alpha.

Results: Some individuals reported negative side effects for all 32 items. However, careful examination of results suggests that, as a whole, reported negative side effects tend to be mild with mean scores falling close to the lower quartile of the total scores. Chi square test results suggest that the variables of age, gender, duration of hearing loss, self-reported hearing disability, and duration of hearing aid use seem to be significantly associated with the reported negative side effects. The NSE-HAs questionnaire was found to have a complex structure as indicated by the principal components analysis. However, good internal consistency was found in both the full scale and subscales.

Conclusions: The present study suggests that, although a large number of adults with hearing loss who use hearing aids experience some degree of negative side effects, those effects tend to be mild.

Key Words: hearing aids, hearing loss, negative effects, side effects

Abbreviations: BTE = behind-the-ear; HLAA = Hearing Loss Association of America; NSE-HA = negative side effects of hearing aid; PCA = principal components analysis

\section{INTRODUCTION}

A side effect (also named adverse event or harmful effect) is an unintended, negative reaction to a medicine or treatment. Adverse side effects are generally secondary to the main therapeutic effect. For example, antibiotics such as gentamicin, which are used to treat a wide variety of bacterial infections (i.e., primary therapeutic effect), can cause damage to outer hair cells (i.e., secondary ototoxic side effect) (Halmagyi

*Department of Speech and Hearing Sciences, Lamar University, Beaumont, TX; +Linnaeus Centre Head, Department of Behavioral Science and Learning, Swedish Institute for Disability Research, Linköping University, Linkoping, Sweden; †Audiology India, Mysore, Karnataka, India; §Department of Speech and Hearing, School of Allied Health Sciences, Manipal University, Manipal, Karnataka, India; 9 Department of Communication Science and Disorders, University of South Florida, Tampa, FL; ||Hearing Tracker Inc, Austin, TX; \#Department of Behavioral Sciences and Learning, Linkoping University, Linköping, Sweden; ${ }^{\star \star}$ Division of Psychiatry, Department of Clinical Neuroscience, Karolinska Institute, Stockholm, Sweden

Corresponding author: Dr. Vinaya Manchaiah, Department of Speech and Hearing Sciences, Lamar University, Beaumont, TX 77710; Email: vinaya.manchaiah@lamar.edu

Authors Vinaya Manchaiah, Harvey Abrams, and Gerhard Andersson report no conflict of interest. Abram Bailey is the President and CEO of Hearing Tracker Inc. 
et al, 1994). Unintended side effects can be caused by medications and treatments, recommended by health professionals, and by self-administered over-the-counter treatments and alternative therapies (Celano et al, 2011). The U.S. Food and Drug Administration will only approve the treatment and/or medication if the basic safety and efficacy of the treatment is demonstrated and the benefits outweigh its risks (U.S. Food and Drug Administration, 2017). However, not everything can be known about a treatment's or medication's side effects until after it enters the market place and more people start using them. Hence, postmarketing surveillance with input from health professionals and consumers can help better understand the adverse effects that may be seen in the real world.

The side effects of treatment and/or medications may not be experienced by all users. Moreover, there may be variations of one or more side effects from the same treatment and each individual may experience such effects to a milder or more severe degree. We believe that the knowledge and understanding of the side effects are important for both health professionals and the consumers for the following reasons: (1) to improve appropriate treatment/ medication choices; (2) to establish appropriate expectations about benefits and limitations of the treatment; and (3) to help anticipate and manage the side effects. Although it is common to study the negative side effects associated with medications and medical interventions, a focus on rehabilitation interventions such as hearing aids is unusual. The investigation of negative effects is warranted, even if they are rare, as both policy makers and consumers may need that information to make informed decisions and manage expectations about treatment.

Hearing loss is one of the most frequent chronic conditions in older adults (National Institute on Deafness and Communication Disorders, 2017) resulting in physical, mental, and social consequences (Chia et al, 2007) that may also extend to their significant others (Manchaiah et al, 2012). Although the management of hearing loss may consist of several treatment options, hearing aids are the most frequently employed rehabilitation option for addressing communication problems related to hearing loss (Laplante-Lévesque et al, 2010). However, the latest MarkeTrak results suggest that about $5 \%$ of hearing aid owners report that they never wear their hearing aids (Abrams and Kihm, 2015), which may be related to negative side effects. However, it is important to note that the side effects can also occur among individuals who are frequent hearing aid users. For example, Kochkin (2000) reported that close to 100,000 consumers complained of side effects such as pressure in the ear, blisters in the ear, ear that sweat, wax buildup in the ear canal, headaches, problems in chewing and swallowing. Other researchers have indirectly studied negative side effects through a focus on nonuse of hearing aids (McCormac and Fortnum, 2013; Ng and Loke, 2015). Moreover, questionnaires related to hearing aid benefit, such as the abbreviated profile of hearing aid benefit (Cox and Alexander, 1995), contain questions that explore specific hearing aid side effects (e.g., aversiveness of sound). Despite these examples, there appears to be limited literature specifically focusing on negative side effects of hearing aid (NSE-HA) use.

The present study was aimed at determining and classifying the negative side effects associated with hearing aid use in adults with hearing loss. The specific aims included (1) developing a questionnaire to study the NSE-HAs; (2) studying the side effects reported by adult hearing aid users and examining their relationship with demographic factors; and (3) examining the psychometric properties (i.e., factor structure and internal consistency) of the questionnaire.

\section{METHOD}

\section{Ethical Considerations}

Ethical approval (IRB no. 7341768) was obtained from the Institutional Review Board, Office of Research and Sponsored Programs, Lamar University, Beaumont, TX.

\section{Study Design and Sample}

The study used a cross-sectional survey design. A web-based survey (i.e., Survey Monkey) was sent to members of Hearing Loss Association of America (HLAA) and Hearing Tracker.

HLAA is the leading nonprofit organization representing the deaf and hard of hearing people in the United States. HLAA provides assistance for people with hearing loss and their significant others in learning to live with hearing loss. The organization conducts various activities, including raising public awareness about the need for prevention, treatment, and about regular hearing assessment. Hearing Tracker is a private entity which serves as a consumer-led website to promote best practice in audiology and to provide comprehensive and unbiased information about hearing instruments and practices. Each organization has $>5,000$ users (mainly people with hearing loss) who subscribe to their mailing list. Following review and approval of the survey, each organization sent the survey link to their members via email.

A total of 526 participants registered for the survey of which 512 fully completed the questionnaire that were considered for further analysis. It is impossible to precisely know the number of questionnaires that were completed by participants representing each member organization. However, the survey was sent out on different dates to members of the two organizations. Based on the date of the response received, we estimate that about $80 \%$ of responses are from Hearing Tracker members, whereas the remaining $20 \%$ are from HLAA members. 


\section{Questionnaire}

As we could find no previous study examining hearing aid side effects, we developed the NSE-HAs questionnaire for this investigation. Items for the questionnaire were derived primarily through discussion among research team members considering previous literature on negative side effects reported by hearing aid users (Kochkin, 2000; McCormac and Fortnum, 2013; Ng and Loke, 2015). The structured questionnaire included 32 items (see Appendix) representing three domains: physical (items 1-17), psychological (items 18-27), and social (items 28-32). The physical subscale included items related to both physical aspects of device (e.g., feedback) and the physical nature of the person (e.g., headache and ear pain). However, the psychological and social subscales included items related to effects noticed by the person. The survey questions had a five-point response scale, which included: $0=\mathrm{I}$ do not experience this side effect; $1=$ This side effect is not a problem for me (although I experience it); 2 = This side effect is a small problem for me; $3=$ This side effect is a medium problem for me; and $4=$ This side effect is a big problem for me. The range of the total score is 0 to 128 (i.e., 32 items multiplied by the response rating).

\section{Data Analysis}

The data were analyzed using the IBM SPSS version 20. Descriptive statistics were explored. Nonparametric statistics were chosen as the Shiparo-Wilk test showed that the data failed the assumption of normality. Spearman's correlation was performed to study the association between subscales and the full scale. Chi square testing was performed to examine the relationship between demographic factors and specific negative side effects. For performing the Chi square analysis, continuous demographic variables (i.e., age, duration of hearing loss, duration of hearing aid use, and hearing aid use in day) were converted into categorical variables by splitting the variables to above and below the median value. A $p$-value of 0.05 was considered as significant for all interpretations.

Exploratory factor analysis was performed using principal components analysis (PCA) with varimax rotation to examine the dimensionality of the item set measuring the construct (i.e., factor structure). Factors were extracted based on eigenvalues identified in the screen plot, item factor loading $(r>0.40)$. Cronbach's alpha $(\alpha)$ was used to investigate the internal consistency. A Cronbach's alpha ranging between 0.70 and 0.95 was classified as good.

\section{RESULTS}

\section{Sample Demographics}

The study sample included 512 adults $(60 \%$ male and $40 \%$ female) with hearing loss who reported to be regular hearing aid users (see Table 1). The mean age of the participants was 64 years with a mean duration of hearing loss of 23 years. Nearly $85 \%$ of participants used behind-the-ear (BTE) hearing aids with a mean duration of hearing aid use of 15 years and mean hearing aid use per day of 12.5 hours.

\section{NSE-HAs}

Table 2 presents the percentage of responses for each question, the mean, standard deviation, and the $95 \%$ confidence interval. The response "I don't experience this side effect" was coded as having no side effect, whereas any other response was coded as experiencing some degree of side effect. For seven questions (i.e., Item 5-Headache, Item 9-Too much pressure, Item 12-Blisters, Item 14-Dizziness, Item 16-Hairs getting caught, Item 17-Problem chewing or swallowing, and Item 18-Nervous) fewer than 30\% reported experiencing any degree of side effects. For four questions (i.e., Item 2-Poor sound quality, Item 3-Sounds are uncomfortably loud, Item 4-Sounds are too soft, Item 23Afraid of missing out in conversation), $>70 \%$ reported experiencing some degree of negative side effects.

Table 1. Demographic Information

\begin{tabular}{|c|c|c|}
\hline Variables & Mean \pm SD & $\%$ \\
\hline Age (in years) & $64.21 \pm 14.3$ & \\
\hline $\begin{array}{l}\text { Duration of hearing loss } \\
\text { (in years) }\end{array}$ & $23.44 \pm 19.3$ & \\
\hline $\begin{array}{l}\text { Duration of hearing aid use } \\
\text { (in years) }\end{array}$ & $15.33 \pm 15.9$ & \\
\hline $\begin{array}{l}\text { Hearing aid use in a day } \\
\text { (in hours) }\end{array}$ & $12.50 \pm 4.16$ & \\
\hline $\begin{array}{l}\text { Hearing aid use in a week } \\
\text { (in days) }\end{array}$ & $6.52 \pm 1.21$ & \\
\hline \multicolumn{3}{|l|}{ Gender } \\
\hline Male & & 60.2 \\
\hline Female & & 39.8 \\
\hline \multicolumn{3}{|l|}{ Hearing loss } \\
\hline Both ears & & 91.8 \\
\hline Right ear & & 3.5 \\
\hline Left ear & & 4.5 \\
\hline Not sure & & 0.2 \\
\hline \multicolumn{3}{|l|}{$\begin{array}{l}\text { Self-reported hearing } \\
\text { disability without hearing } \\
\text { aids }\end{array}$} \\
\hline None & & 1.4 \\
\hline Small & & 11.1 \\
\hline Medium & & 33.4 \\
\hline Large & & 53.9 \\
\hline Not sure & & 0.2 \\
\hline \multicolumn{3}{|l|}{ Type of hearing aids used } \\
\hline BTE & & 84.4 \\
\hline In the ear & & 7.8 \\
\hline In the canal & & 6.3 \\
\hline Unsure & & 1.6 \\
\hline
\end{tabular}


Table 2. NSE-HAs (Percentage of Responses for Each Question, Mean, Standard Deviation, and 95\% Confidence Intervals)

\begin{tabular}{|c|c|c|c|c|c|c|c|}
\hline \multirow[b]{2}{*}{ Items } & \multicolumn{5}{|c|}{$\%$ of Respondents } & \multirow[b]{2}{*}{ Mean $\pm S D$} & \multirow[b]{2}{*}{$\begin{array}{l}95 \% \mathrm{Cl} \\
\text { (Lower to } \\
\text { upper) }\end{array}$} \\
\hline & $\begin{array}{c}\text { I Don't } \\
\text { Experience } \\
\text { This Side } \\
\text { Effect }\end{array}$ & $\begin{array}{l}\text { This Side Effect } \\
\text { is Not a Problem } \\
\text { for Me (Although } \\
\text { I Experience It) }\end{array}$ & $\begin{array}{l}\text { This Side Effect } \\
\text { is a Small } \\
\text { Problem for Me }\end{array}$ & $\begin{array}{l}\text { This Side Effect } \\
\text { is a Medium } \\
\text { Problem for Me }\end{array}$ & $\begin{array}{c}\text { This Side Effect } \\
\text { is a Big Problem } \\
\text { for Me }\end{array}$ & & \\
\hline \multicolumn{8}{|c|}{ Physical effects (Cronbach's alpha of 0.85 ) } \\
\hline Feedback noise & 38.5 & 21.1 & 25.6 & 10.2 & 4.7 & $1.21 \pm 1.2$ & $1.10-1.31$ \\
\hline Poor sound quality & 29.9 & 14.3 & 21.5 & 21.9 & 12.5 & $1.73 \pm 1.4$ & $1.61-1.85$ \\
\hline $\begin{array}{l}\text { Sounds are } \\
\text { uncomfortably loud }\end{array}$ & 27.3 & 18.4 & 25.5 & 18.4 & 10.5 & $1.66 \pm 1.3$ & $1.54-1.78$ \\
\hline Sounds are too soft & 14.3 & 11.1 & 20.5 & 24.2 & 29.9 & $2.44 \pm 1.4$ & $2.32-2.56$ \\
\hline Headache & 80.7 & 6.8 & 7.0 & 3.3 & 2.1 & $0.39 \pm 0.9$ & $0.32-0.48$ \\
\hline Tinnitus & 39.6 & 18.4 & 15.6 & 13.7 & 12.7 & $1.41 \pm 1.4$ & $1.29-1.54$ \\
\hline Bad fitting & 64.6 & 12.1 & 10.7 & 8.2 & 4.3 & $0.75 \pm 1.2$ & $0.65-0.86$ \\
\hline Ear pain & 65.8 & 13.5 & 12.1 & 6.3 & 2.3 & $0.66 \pm 1.0$ & $0.57-0.75$ \\
\hline Too much pressure & 73.0 & 13.7 & 8.0 & 3.9 & 1.4 & $0.47 \pm 0.9$ & $0.39-0.55$ \\
\hline Plugged or fullness & 54.9 & 19.7 & 14.3 & 7.4 & 3.7 & $0.85 \pm 1.1$ & $0.76-0.96$ \\
\hline Itching and/or rashes & 39.1 & 23.4 & 20.1 & 11.1 & 6.3 & $1.22 \pm 1.2$ & $1.11-1.33$ \\
\hline Blisters & 91.8 & 2.1 & 3.9 & 1.4 & 0.8 & $0.17 \pm 0.6$ & $0.11-0.22$ \\
\hline Sweating or moisture & 54.9 & 18.4 & 14.1 & 6.6 & 6.1 & $0.91 \pm 1.2$ & $0.80-1.02$ \\
\hline Dizziness & 79.1 & 8.2 & 6.4 & 4.3 & 2.0 & $0.42 \pm 0.9$ & $0.34-0.50$ \\
\hline Wax build up & 36.7 & 24.4 & 19.5 & 14.1 & 5.3 & $1.27 \pm 1.2$ & $1.16-1.37$ \\
\hline Hairs getting caught & 74.2 & 13.1 & 8.0 & 4.3 & 0.4 & $0.44 \pm 0.8$ & $0.36-0.51$ \\
\hline $\begin{array}{l}\text { Problems chewing or } \\
\text { swallowing }\end{array}$ & 86.3 & 7.4 & 3.5 & 2.3 & 0.4 & $0.23 \pm 0.6$ & $0.17-0.29$ \\
\hline \multicolumn{8}{|c|}{ Psychological effects (Cronbach's alpha of 0.87 ) } \\
\hline Nervous & 81.5 & 6.3 & 7.0 & 3.5 & 1.8 & $0.38 \pm 0.9$ & $0.30-0.46$ \\
\hline Isolated & 63.9 & 8.2 & 12.5 & 8.0 & 7.4 & $0.87 \pm 1.3$ & $0.75-0.98$ \\
\hline Old & 65.8 & 14.5 & 10.5 & 5.7 & 3.5 & $0.67 \pm 1.1$ & $0.56-0.75$ \\
\hline $\begin{array}{l}\text { Reduced self } \\
\text { confidence }\end{array}$ & 58.6 & 10.9 & 12.5 & 10.0 & 8.0 & $0.98 \pm 1.3$ & $0.85-1.09$ \\
\hline Financial stress & 47.5 & 13.3 & 11.4 & 14.1 & 13.9 & $1.34 \pm 1.5$ & $1.20-1.46$ \\
\hline $\begin{array}{l}\text { Afraid of missing out } \\
\text { in conversations }\end{array}$ & 17.4 & 12.3 & 19.9 & 20.5 & 29.9 & $2.34 \pm 1.4$ & $2.20-2.46$ \\
\hline $\begin{array}{l}\text { Afraid of being } \\
\text { responsible for } \\
\text { conversations }\end{array}$ & 35.6 & 12.7 & 18.4 & 17.2 & 16.2 & $1.66 \pm 1.5$ & $1.52-1.78$ \\
\hline $\begin{array}{l}\text { Afraid of becoming } \\
\text { dependent on the } \\
\text { device }\end{array}$ & 54.6 & 15.1 & 13.3 & 7.8 & 9.2 & $1.02 \pm 1.3$ & $0.89-1.12$ \\
\hline $\begin{array}{l}\text { Afraid that hearing } \\
\text { aids will stop working }\end{array}$ & 35.6 & 24.9 & 18.4 & 11.5 & 9.6 & $1.35 \pm 1.3$ & $1.22-1.45$ \\
\hline $\begin{array}{l}\text { Fear of losing or } \\
\text { destroying hearing } \\
\text { aids }\end{array}$ & 32.9 & 19.4 & 19.8 & 14.5 & 13.5 & $1.56 \pm 1.4$ & $1.43-1.68$ \\
\hline \multicolumn{8}{|c|}{ Social effects (Cronbach's alpha of 0.84 ) } \\
\hline $\begin{array}{l}\text { Other people treating } \\
\text { with less respect }\end{array}$ & 66.2 & 10.4 & 11.8 & 7.5 & 4.1 & $0.73 \pm 1.2$ & $0.63-0.83$ \\
\hline People avoiding & 69.9 & 10.8 & 10.4 & 5.1 & 3.7 & $0.62 \pm 1.0$ & $0.52-0.71$ \\
\hline People staring & 74.5 & 14.5 & 6.3 & 3.1 & 1.6 & $0.43 \pm 0.9$ & $0.35-0.50$ \\
\hline People talking louder & 52.7 & 24.4 & 14.3 & 6.3 & 2.4 & $0.81 \pm 1.0$ & $0.72-0.90$ \\
\hline People talking softer & 75.8 & 10.0 & 8.8 & 2.6 & 2.8 & $0.46 \pm 0.9$ & $0.38-0.55$ \\
\hline
\end{tabular}


Please note that in this context the reports of "afraid of missing out in conversation" refers to missing out in conversation while using hearing aids because of poor sound quality. For the remaining twenty questions, the percentage of individuals reporting negative side effects ranged between $30 \%$ and $70 \%$. These results indicate that a large percentage of adults with hearing loss who use hearing aids experience at least some negative side effects, which are primarily described as mild.

Table 3 presents the descriptive statistics for the full scale and the three subscales of the NSE-HA questionnaire. Examination of the results suggests that, as a whole, the reported negative side effects are mild with mean scores falling close to the lower quartile of the total scores. Also, there was a strong positive correlation (correlation coefficient $>0.70$ ) between the full-scale score and each of the three subscales. The three subscales were also positively correlated with each other (correlation coefficient $=0.30-0.70)$ (Table 4).

Chi square analysis was performed between the negative side effects full-scale responses and the demographic variables. Results suggest that the variables of age, gender, duration of hearing loss, self-reported hearing disability, and duration of hearing aid use are significantly associated with reported negative side effects (see Table 5).

\section{Psychometric Properties of NSE-HA Questionnaire}

\section{Factor Structure}

The PCA with Varimax rotation was performed. The Kaiser-Meyer-Olkin measure of sampling adequacy was found to be 0.92 with a reference value of $0-1.0$, and Bartlett's test of sphericity was significant $\left[\chi^{2}(496)=\right.$ $6,154.3, p \leq 0.0001]$. The PCA resulted in a seven-factor structure, which explained $58.78 \%$ of the variance in the 32-item scale (see Table 6). These factors were named as (1) psycho-social aspects; (2) physical fit of hearing device; (3) hearing device sound quality and understanding conversation; (4) anxiety; (5) self-image; (6) physical sensations; and (7) wax-related.

\section{Internal Consistency}

The Cronbach's alpha of full scale was 0.92 . The physical (items 1-17), psychological (items 18-27), and social subscales (items 27-32) had Cronbach's alpha of $0.85,0.87$ and 0.84 , respectively. These values suggest good internal consistency of both the full scale and each subscale.

\section{DISCUSSION}

$\mathrm{H}$ earing aid use is associated with many benefits, including improved health related quality of life (Chisolm et al, 2007; Niemensivu et al, 2015). Although it is common and essential to study the benefits of hearing aids, it would also be useful to study the negative effects of hearing aids use. The present study examined the negative side effects associated with hearing aid use in adults with hearing loss and also the relationship between negative side effects and specific demographic factors. Understanding the nature of these negative side effects is important to providers, the industry, and patients. Marketing studies show that consumers who are unhappy with products or services are twice as likely to share their negative experiences with others than are happy and satisfied customers (Deming, 1982). It is suggested that the benefits and limitations of hearing aids need to be examined as a function of psychological and social constructs in addition to physical constructs (Tesch-Römer, 1997). We argue that examining the NSE-HAs in these same domains is equally important.

The negative side effects reported in this study were primarily associated with the physical domain (i.e., poor sound quality, sounds are uncomfortably loud, sounds are too soft). In addition, there was a high percentage of participants $(>70 \%)$ who reported a side effect on one particular item in the psychological domain (i.e., afraid of missing out in conversation). In contrast, there were a number of items for which very few individuals reported experiencing side effects (i.e., headache, too much pressure, blisters, dizziness, hairs getting caught, problem chewing or swallowing, and nervous). It is important to note, however, that the negative side effects

Table 3. Mean, Standard Deviation, Median, Range, and 95\% Confidence Intervals for the NSE-HAs Questionnaire Full-Scale and Sub-Scales

\begin{tabular}{lcccccc}
\hline & & & & \multicolumn{2}{c}{$95 \% \mathrm{Cl}$} \\
\cline { 5 - 7 } Scale & Score Range & Mean \pm SD & Median & Range & Lower & Upper \\
\hline Full scale (32 items) & $0-128$ & $31.4 \pm 22.5$ & 27 & $1-100$ & 29.6 & 33.2 \\
Physical effects (17-items) & $0-68$ & $16.2 \pm 10.5$ & 14 & $0-55$ & 15.3 & 17.1 \\
Psychological effects (10-items) & $0-40$ & $12.1 \pm 8.9$ & 10 & $0-40$ & 11.3 & 12.9 \\
Social effects (5-items) & $0-20$ & $3.05 \pm 4.0$ & 1 & $0-20$ & 2.7 & 3.4 \\
\hline
\end{tabular}


Table 4. Spearman's Correlation between Full-Scale and Sub-Scales

\begin{tabular}{|c|c|c|c|}
\hline & $\begin{array}{l}\text { Full- } \\
\text { Scale }\end{array}$ & $\begin{array}{l}\text { Physical } \\
\text { Effects }\end{array}$ & $\begin{array}{c}\text { Psychological } \\
\text { Effects }\end{array}$ \\
\hline Physical effects & $0.89^{*}$ & & \\
\hline $\begin{array}{l}\text { Psychological } \\
\text { effects }\end{array}$ & $0.90^{*}$ & $0.63^{*}$ & \\
\hline Social effects & $0.73^{\star}$ & $0.54^{*}$ & $0.65^{*}$ \\
\hline
\end{tabular}

reported by a large number of hearing aid users were perceived as mild. Also, some of the side effects reported such as, "Sounds are too soft" or "Afraid of missing out on conversation" may be related more to severity of hearing loss than to the hearing aids used. The side effects of hearing aids that would warrant greatest concern from a medical perspective include complaints related to headache, blisters, and dizziness. However, very few people reported these kinds of effects in the present study.

A recent literature review suggested that some audiological variables (e.g., severity of hearing loss, type of hearing aid, background noise acceptance, and insertion gain) and nonaudiological variables (self-reported hearing disability, expectations, demographics, group consultation, support from significant others, self-perceived benefit, satisfaction) were found to be determinants of hearing aid adoption and use among elderly individuals with hearing loss (Ng and Loke, 2015). The present study showed that specific audiological and nonaudiological variables including age, gender, duration of hearing loss, self-reported hearing disability, and duration of hearing aid use are significantly associated with reported negative side effects.

The items of the NSE-HA questionnaire are categorized into three sections (i.e., physical effects, psychological effects and social effects). However, the questionnaire was found to have a complex structure as indicated by the PCA. One possible reason for this could be the geographically diverse population included in the Internet-based recruitment. Although the diverse population increases the generalizability of the study results, the complex factor structure may be attributed to this diversity. More coherent characteristics in sample may have resulted in simpler factor structure. Hence, administering this questionnaire in a clinical population may provide more useful findings about the questionnaire factor structure. Nevertheless, good internal consistency was found in both the full scale and subscales suggesting questions within each section were measuring the same construct. Further work is necessary to examine various psychometric properties including construct, concurrent and predictive validities of the NSE-HA questionnaire.

\section{Study Implications}

It is a common practice, in the general medical community, to discuss the adverse effects of a treatment and/or medication with the patient (Faden et al, 1981). Hearing health professionals should also discuss the possible NSE-HA use with their patients and their communication partners during the hearing aid fitting and orientation process. In addition, information about NSE-HAs can also be included with the patient information materials and hearing aid user manuals. It has been suggested that including information about side effects in patient leaflet could help set appropriate expectations from the intervention (Webster et al, 2017).

\section{Study Limitations and Future Directions}

This study is the first of its kind to specifically examine the NSE-HA use. However, it has limitations. The sample was recruited through patient organizations using the Internet, which may represent different demographic characteristics when compared with a typical clinical population. Also, all participants were selfselected as regular hearing aid users. For these reasons, the participant sample may have been at risk of sample bias. An additional limitation is that the NSE-HA questionnaire, which was developed for the purpose of this study, has not yet been validated. Also, most participants (i.e., nearly $85 \%$ ) were BTE hearing aid users. Hence, the current study provides information about the negative side effects of BTE hearing aids as perceived by

Table 5. Association between Demographic Variables and Negative Side Effects (Factors Found to Be Significant below p-Value of 0.05 Are Highlighted)

\begin{tabular}{|c|c|c|c|c|}
\hline Variables & Chi Square & Sig. & Phi & Cramer's V \\
\hline Age (in years) & 17.4 & 0.0001 & -0.184 & 0.184 \\
\hline Gender & 5.5 & 0.02 & 0.104 & 0.104 \\
\hline Duration of hearing loss (in years) & 9.55 & 0.002 & 0.137 & 0.137 \\
\hline Hearing loss (which ear) & 2.8 & 0.41 & 0.075 & 0.075 \\
\hline Self-reported hearing disability & 21.7 & 0.0001 & 0.206 & 0.206 \\
\hline Type of hearing aids used & 0.66 & 0.88 & 0.036 & 0.036 \\
\hline Duration of hearing aid use (in years) & 9.5 & 0.002 & 0.136 & 0.136 \\
\hline Hearing aid use in a day & 1.58 & 0.21 & -0.056 & 0.056 \\
\hline
\end{tabular}


Table 6. NSE-HA Seven Factor PCA

\begin{tabular}{|c|c|c|c|c|c|c|c|}
\hline \multirow[b]{2}{*}{ Items } & \multicolumn{7}{|c|}{ Factor Loading } \\
\hline & $\begin{array}{c}\text { Factor 1: } \\
\text { Psycho-Social } \\
\text { Aspects }\end{array}$ & $\begin{array}{c}\text { Factor 2: } \\
\text { Physical Fit of } \\
\text { Hearing Device }\end{array}$ & $\begin{array}{l}\text { Factor 3: Hearing } \\
\text { Device Sound } \\
\text { Quality and } \\
\text { Understanding } \\
\text { Conversation }\end{array}$ & $\begin{array}{c}\text { Factor 4: } \\
\text { Anxiety }\end{array}$ & $\begin{array}{l}\text { Factor 5: } \\
\text { Self-Image }\end{array}$ & $\begin{array}{l}\text { Factor 6: } \\
\text { Physical } \\
\text { Sensations }\end{array}$ & $\begin{array}{c}\text { Factor } 7: \\
\text { Wax-Related }\end{array}$ \\
\hline 1 & & & & & & & \\
\hline 2 & & & 0.692 & & & & \\
\hline 3 & & & 0.618 & & & & \\
\hline 4 & & & 0.684 & & & & \\
\hline 5 & & & & & & 0.587 & \\
\hline 6 & & & & & & 0.556 & \\
\hline 7 & & 0.612 & & & & & \\
\hline 8 & & 0.710 & & & & & \\
\hline 9 & & 0.684 & & & & & \\
\hline 10 & & 0.586 & & & & & \\
\hline 11 & & 0.646 & & & & & \\
\hline 12 & & 0.503 & & & & & \\
\hline 13 & & 0.524 & & & & & \\
\hline 14 & & & & & & 0.690 & \\
\hline 15 & & & & & & & 0.633 \\
\hline 16 & & & & & & 0.471 & \\
\hline 17 & & & & & 0.420 & & \\
\hline 18 & & & & & 0.634 & & \\
\hline 19 & 0.553 & & & & 0.476 & & \\
\hline 20 & & & & & 0.564 & & \\
\hline 21 & 0.560 & & & & 0.490 & & \\
\hline 22 & & & & 0.559 & & & \\
\hline 23 & & & 0.608 & & & & \\
\hline 24 & & & 0.505 & & & & \\
\hline 25 & & & & 0.614 & & & \\
\hline 26 & & & & 0.758 & & & \\
\hline 27 & & & & 0.801 & & & \\
\hline 28 & 0.770 & & & & & & \\
\hline 29 & 0.771 & & & & & & \\
\hline 30 & 0.625 & & & & & & \\
\hline 31 & 0.722 & & & & & & \\
\hline 32 & 0.549 & & & & & & \\
\hline Eigen value & 4.048 & 3.453 & 2.961 & 2.838 & 2.211 & 2.086 & 1.214 \\
\hline $\begin{array}{c}\text { Percentage of } \\
\text { variance }\end{array}$ & 12.649 & 10.791 & 9.255 & 8.869 & 6.908 & 0.518 & 3.794 \\
\hline $\begin{array}{l}\text { Cumulative } \\
\text { percentage of } \\
\text { variance }\end{array}$ & 12.649 & 23.439 & 32.694 & 41.564 & 48.471 & 54.989 & 58.784 \\
\hline
\end{tabular}

long-term hearing aid users but provides limited information on custom hearing aid users. That said, the distribution of hearing aid styles among the participants in this study is generally representative of that in the hearing aid user population in the United States (Hearing Review, 2017). It is also possible that the type of BTE (standard BTE, receiver in canal [RIC]) and the ear mould used may have contributed to the presence or absence of the negative side effects reported. Unfortunately, we did not collect this information. Finally, recruitment of participants from patient organization and consumer-led websites may have led to an overrepresentation of individuals with more se- vere hearing disability (i.e., $>50 \%$ participants reporting large disability), which limits the generalizability of these results to those with mild to moderate hearing loss. Future studies should account for the limitations identified here and examine other factors not explored (e.g., health literacy, cognitive ability, degree of hearing loss, hearing device manufacturer, hearing aid features, and how long the current hearing aids are being used) that might influence the occurrence of negative side effects. Future studies might benefit from methods such as Ecological Momentary Assessment to collect real-time data (e.g., Wu et al, 2015). 


\section{CONCLUSIONS}

$\mathrm{T}$ he present study suggests that a large number of adult hearing aid users experience some degree of negative side effects although most of those effects are described as mild. Hearing health professionals and hearing aid users should be aware of the common NSE-HAs. Knowledge and understanding of the side effects may help to improve treatment planning, establish appropriate expectations, and yield optimal outcomes.

Acknowledgments. The authors acknowledge Hearing Loss Association of America (HLAA) and Hearing Tracker Inc. for help with data collection.

\section{REFERENCES}

Abrams HB, Kihm J. (2015) An introduction to MarkeTrak IX: a new baseline for hearing aid market. Hearing Rev 22(6):16.

Celano CM, Freudenreich O, Fernandez-Robles C, Stern TA, Caro MA, Huffman JC. (2011) Depressogenic effects of medications: a review. Dialogues Clin Neurosci 13(1):109-125.

Chia EM, Wang JJ, Rochtchina E, Cumming RR, Newall P, Mitchell P. (2007) Hearing impairment and health-related quality of life: the Blue Mountains hearing study. Ear Hear 28:187-195.

Chisolm TH, Johnson CE, Danhauer JL, Portz LJ, Abrams HB, Lesner S, McCarthy PA, Newman CW. (2007) A systematic review of health-related quality of life and hearing aids: final report of the American Academy of Audiology task force on the health-related quality of life benefits of amplification in adults. J Am Acad Audiol 18:151-183

Cox RM, Alexander GC. (1995) The abbreviated profile of hearing aid benefit. Ear Hear 16:176-186.

Deming WE. (1982) Out of the Crisis. Cambridge, MA: MIT Center for Engineering Study.

Faden RR, Becker C, Lewis C, Freeman J, Faden AI. (1981) Disclosure of information to patients in medical care. Med Care 19(7): 718-733.
Halmagyi GM, Fattore CM, Curthoys IS, Wade S. (1994) Gentamicin vestibulotoxicity. Otolaryngol Head Neck Surg 111:571-574.

Hearing Review. (2017) US Hearing Aid Sales Increased by 8.7\% in 2016. http://www.hearingreview.com/2017/01/us-hearing-aidunit-sales-increased-8-7-2016/. Accessed March 4, 2018.

Kochkin S. (2000) MarkTrak V: "Why my hearing aids are in the drawer": the consumers' perspective. Hearing $J$ 53(2):34-41.

Laplante-Lévesque A, Hickson L, Worrall L. (2010) Rehabilitation of older adults with hearing impairment: a critical review. J Aging Health 22:143-153.

Manchaiah VKC, Stephens D, Zhao F, Kramer SE. (2012) The role of communication partners in the audiological enablement/ rehabilitation of a person with hearing impairment: a discussion paper. Audiological Med 10:21-30.

McCormack A, Fortnum H. (2013) Why do people fitted with hearing aids not wear them? Int J Audiol 52:360-368.

National Institute on Deafness and Communication Disorders. (2017) Hearing Loss and Older Adults. https://www.nidcd.nih.gov/health/hearing-loss-older-adults. Accessed June 20, 2017.

Ng JH-Y, Loke AY. (2015) Determinants of hearing-aid adoption and use among the elderly: a systematic review. Int J Audiol 54: 291-300.

Niemensivu R, Manchaiah V, Roine R, Sintonen H, Kentala E. (2015) Health-related quality of life in adults with hearing impairment before and after hearing-aid rehabilitation in Finland. Int $J$ Audiol 54:967-975.

Tesch-Römer C. (1997) Psychological effects of hearing aid use in older adults. J Gerontol B Psychol Sci Soc Sci 52(3):P127-P138.

U.S. Food and Drug Administration. (2017) Learning about Side Effects. https:/www.fda.gov/drugs/resourcesforyou/consumers/ ucm196029.htm. Accessed June 20, 2017.

Webster RK, Weinman J, Rubin GJ. (2017) How does the side-effect information in patient information leaflets influence peoples' sideeffect expectations? A cross-sectional national survey of 18- to 65year-olds in England. Health Expect 20(6):1411-1420.

Wu Y-H, Stangl E, Zhang X, Bentler R. (2015) Construct validity of the ecological momentary assessment in audiology research. J Amer Acad Audiol 26(10):872-884. 


\section{Appendix}

\section{NSE-HAs Questionnaire}

\section{Structured Questionnaire}

Response Scale and Scoring: 0 = I don't experience this side effect; 1 = This side effect is not a problem for me (although I experience it); 2 = This side effect is a small problem for me; $3=$ This side effect is a medium problem for me; $4=$ This side effect is a big problem for me.

\section{Physical Effects}

When you wear your hearing aids, do you experience:

1. Feedback noise (e.g., whistling)?

2. Poor sound quality?

3. Sounds that are uncomfortably loud?

4. Sounds that are too soft to hear?

5. Headaches?

6. Tinnitus (ringing or buzzing in your ears)?

7. Bad fitting?

8. Ear pain?

9. Too much pressure in the ear?

10. Plugged or fullness sensation in your ears?

11. Itching and/or rashes in or on your ears?

12. Blisters in the ears?

13. Sweating or moisture in the ears?

14. Dizziness?

15. Wax build up?

16. Hairs getting caught in your hearing aids?

17. Problems chewing or swallowing?

\section{Psychological Effects}

When you wear your hearing aids do you feel:

18. Nervous?

19. Isolated?

20. Old?

21. Reduced self-confidence?

22. Financial stress?

23. Afraid of missing out in conversations? 
24. Afraid of being more responsible for listening in conversations?

25. Afraid of becoming dependent on the device?

26. Afraid that your hearing aids will stop working and/or batteries will run out?

27. Fear of losing or destroying your hearing aids?

\section{Social Effects}

When you wear your hearing aids do you notice:

28. Other people treating you with less respect?

29. People avoiding you?

30. People staring at you (or your ears)?

31. People talking louder when they see your hearing aids?

32. People talking softer when they see your hearing aids? 